\title{
Practice of immediate sequential bilateral cataract surgery (ISBCS) since COVID-19: a patient and surgeon survey
}

\author{
Haoyu Wang $\mathbb{D}^{1} \cdot$ Vipul Ramjiani $^{1} \cdot$ Mathew Raynor ${ }^{1} \cdot$ Jennifer $\operatorname{Tan}^{1}$ \\ Received: 28 February 2021 / Revised: 6 March 2021 / Accepted: 25 March 2021 / Published online: 6 April 2021 \\ (c) The Author(s), under exclusive licence to The Royal College of Ophthalmologists 2021
}

\section{To the Editor:}

We read with interest the article by Naderi et al. [1] and were intrigued by their finding of patients' shifted preference towards immediate sequential bilateral cataract surgery (ISBCS) as a result of COVID-19. The COVID-19 pandemic has brought enormous challenges to ophthalmic service delivery in United Kingdom (UK) after postponement of elective clinical activities including cataract surgery during the first wave of pandemic (March- June 2020). New strategies are more needed than ever to redesign cataract service to overcome capacity issues, long waiting lists and patient's fear of increased COVID-19 transmission risk in hospital settings [2]. Not only ISBCS offers advantages of reducing pressure on waiting lists but also reduces hospital visits and COVID-19 exposure risks for patients [3]. The Royal College of Ophthalmologists and UK and Ireland Society of Cataract and Refractive Surgery (UKISCRS) jointly recommended more ISBCS in suitable patients to streamline cataract services [4]. Ophthalmology Department at Sheffield Teaching Hospital followed this recommendation and encouraged its cataract surgeons to utilise ISBCS in appropriate candidates with careful counselling and consenting after the cataract service regained its activities in late July 2020. Here, we evaluated the characteristics of ISBCS case selections pre and post COVID-19 era and aimed to share our experience from both surgeons' and patients' perspectives with ISBCS.

A pre-set questionnaire was sent electronically to all the 17 cataract consultants and principals in our institution. A separate six-question patient survey was used to interview patients who had ISBCS during the 6-month period between

Haoyu Wang

haoyu.wang2@nhs.net

1 Ophthalmology Department, Sheffield Teaching Hospitals NHS Foundation Trust, Sheffield, UK
1 August 2020 and 31 January 2021 by telephone. All the survey responses were anonymous. Two telephone calls were attempted on a different day for each eligible patient. Verbal consent was obtained at the start of the interview. First-eye patients who required cataract surgery in both of their eyes were searched on Medisoft from 1 August 2020 to 31 January 2021 (post reopening of cataract service) and from 1 February 2015 to 1 February 2020 (before COVID19) and their pre-op and post-op characteristics were collated. Categorical and continuous variables were tested with chi-squared test and $t$ test respectively with $p<0.05$ to justify significance. The study was approved by Clinical Effectiveness Unit in our institution and adhered to the tenets of the Declaration of Helsinki.

There were $3.05 \%$ of patients (24/788) who received ISBCS in the 6-month period following the reopening of cataract service, in comparison to $0.36 \%(44 / 12336)$ in the 5 -year period before COVID-19 $(p<0.001)$. From these periods, two patients required additional interventions postoperatively, whose vision both later recovered to $6 / 6$. There was no other major safety concern for ISBCS in our case selections. Good patient satisfaction with a high discharge rate was yielded (Table 1).

$79 \%$ of the patients (19/24) who had ISBCS responded to telephone interviews. Of this cohort, $68.4 \%$ were positive towards ISBCS when first offered to them in the pre-op clinic and $73.7 \%$ rated a positive experience on the day of surgery. $57.9 \%$ of the patients would still have chosen ISBCS if the COVID-19 pandemic did not exist. After the experience of having same-day bilateral cataract surgery, $79 \%$ of the patients would recommend it to friends and family. Although few patients voiced negative experience (detailed in Table 2) they would still have chosen ISBCS due to advantages of fewer hospital visits, only one period of self-isolation required and faster binocular visual rehabilitation to avoid issues such as anisometropia.

Sixteen of 17 independent cataract surgeons (13 consultants and 3 principals) gave their perspectives on ISBCS, 11 of whom (68.8\%) practised the recommendation of 
Table 1 Pre-, peri- and post-operative characteristics of all the patients who received immediate sequential bilateral cataract surgery (ISBCS) 5 years before COVID-19 (Feb 2015- Feb 2020) and 6 months following cataract service were resumed after the initial halt of elective services due to the COVID-19 pandemic (Aug 2020 to Feb 2021).

\begin{tabular}{|c|c|c|c|}
\hline & $\begin{array}{l}\text { Aug } 2020 \text { to } \\
\text { Feb } 2021\end{array}$ & Feb 2015 to Feb 2020 & $P$ value \\
\hline $\begin{array}{l}\text { First-eye patients (requiring cataract surgery } \\
\text { in both eyes) }\end{array}$ & 788 & 12,336 & \\
\hline Female & $460(58.4 \%)$ & $7073(57.3 \%)$ & 0.567 \\
\hline Age & $73.8(32-98)$ & $76.8(23-101)$ & 0.377 \\
\hline \multicolumn{4}{|c|}{ Immediate sequential bilateral cataract surgery (ISBCS) } \\
\hline Patients & 24 & 44 & \\
\hline Mean age (range) & $74.1(52-93)$ & $63.7(25-89)$ & 0.045 \\
\hline Female & $15(62.5 \%)$ & $28(63.6 \%)$ & 0.926 \\
\hline General anaesthetic (GA) & $5(20.8 \%)$ & $43(97.7 \%)$ & $<0.001$ \\
\hline Local anaesthetic (LA) & $19(79.2 \%)$ & $1(2.3 \%)$ & $<0.001$ \\
\hline 1st eye performed by consultant/principal & $24(100 \%)$ & $44(100 \%)$ & \\
\hline 2nd eye performed by consultant/principal & $20(83 \%)$ & $36(81.8 \%)$ & \\
\hline \multicolumn{4}{|l|}{ Pre-op risk factor } \\
\hline - Significant head tremor & 2 & 4 & \\
\hline - Mental health issues & 2 & 2 & \\
\hline - Learning disability & 1 & 9 & \\
\hline - Down syndrome & 0 & 9 & \\
\hline - Dementia & 1 & 8 & \\
\hline - Glaucoma & 4 (1 angle closure) & 2 (both angle closure) & \\
\hline - Uveitis & 1 & 0 & \\
\hline - White cataract & 0 & 2 & \\
\hline - Post vitrectomy & 0 & 1 & \\
\hline - 'routine' & 13 (all LA cases) & $\begin{array}{l}7 \text { (all GA cases due to } \\
\text { anxiety/claustrophobia) }\end{array}$ & \\
\hline \multicolumn{4}{|l|}{ Intra-op issues/additional steps } \\
\hline - Zonules instability & 1 (second eye) & 1 (second eye) & \\
\hline - Goniosynechialysis & 1 (angle closure) & 0 & \\
\hline - Pupil expander/hooks & 1 & 2 & \\
\hline \multicolumn{4}{|l|}{ Post-op issues } \\
\hline $\begin{array}{l}\text { - Raised IOP in one eye of a patient who } \\
\text { required AC paracentesis }\end{array}$ & 1 & 0 & \\
\hline $\begin{array}{l}\text { - Ongoing uveitis in a patient with chronic } \\
\text { uveitis }\end{array}$ & 1 & 0 & \\
\hline $\begin{array}{l}\text { - Retained lens matter requiring } \mathrm{AC} \\
\text { washout }\end{array}$ & 0 & 1 (under GA) & \\
\hline Both eyes sutured & $7(29.2 \%)$ & $31(56.8 \%)$ & 0.001 \\
\hline $\begin{array}{l}\text { Patients who were satisfied with post-op } \\
\text { vision or found improvement in quality of life }\end{array}$ & $23(95.8 \%)$ & $42(95.5 \%)$ & \\
\hline \multicolumn{4}{|l|}{ Outcomes } \\
\hline - Discharge & $19(79.2 \%)$ & $38(86.4 \%)$ & \\
\hline - Specialty clinic follow-up & $4(16.7 \%)$ & $4(9.1 \%)$ & \\
\hline - Unknown & $1(4.2 \%)$ & $2(4.5 \%)$ & \\
\hline
\end{tabular}

ISBCS in the wake of the pandemic for the following reasons: college guidance on the matter $(36.4 \%)$, wanting to reduce patient visits $(63.6 \%)$ and successful adoption by colleagues $(9.1 \%)$. Ten surgeons $(90.9 \%)$ rated positive experience with ISBCS overall. Seven surgeons $(63.6 \%)$ have adopted the ISBCS practice for only less than a year. For the five surgeons who chose not to list ISBCS, their main concerns were serious post-op complications 
Table 2 Patients' responses to a pre-set survey conducted by telephone interviews.

1. How did you feel towards the idea when offered bilateral cataract surgery on the same day?

Extremely positive

$2(10.5 \%)$

$11(57.9 \%)$

$6(31.6 \%)$

O Neutral

O Negative

Extremely negative

2. How was your experience on the day of having cataract surgery for both of your eyes?

$\bigcirc$ Extremely positive

O Positive

O Neutral

O Negative

Extremely negative

3. How satisfied were you after attending the pre-op cataract clinic?

Oxtremely positive

O Positive

O Neutral

O Negative

Extremely negative

4. If there was no COVID-19 pandemic, I would still have chosen to have bilateral cataract surgery on the same day?

Strongly agree

O Agree

O Neutral

O Disagree

Strongly disagree

5. Would you recommend having bilateral cataract surgery on the same day to your family or friends

Strongly agree

O Agree

O Neutral

O Disagree

Strongly disagree

6. Was there any concern or issue you experienced during or after surgery for either of your eyes?

$\bigcirc$ "Felt more stressed and scared when second eye was operated by a trainee doctor"

$\bigcirc$ "Theatre was quite noisy and would have preferred a quieter environment"

$\bigcirc$ "My daughter stayed overnight to help with eye drops so in hindsight I would have preferred to have them done on a separate date"

○ "Suffered bell's palsy one month after surgery but it was improving gradually"

$\bigcirc$ "Triggered migraine after the operation"

○ "Operation for second eye took a lot longer. It was more painful and took longer time to recover" (both eyes performed by the same consultant)

0

0
0

$2(10.5 \%)$

(e.g. endophthalmitis) $(40 \%)$, more frequent but less serious post-op complications (e.g. cystoid macular oedema) $(40 \%)$ and refractive surprise $(20 \%)$.

Our experience has demonstrated safe and successful practice of ISBCS recommendation in appropriate case selections at a well-established teaching hospital cataract unit during the COVID-19 pandemic. We hope our experience could be beneficial to other units in the UK and beyond.

Acknowledgements We thank all the patients and surgeons who responded to the survey and provided their valuable perspectives.

Author contributions Concept and design of the work: HW, JT. Acquisition, analysis or interpretation of data: HW, VR, MR, JT. Drafting the manuscript or revising it critically: HW, VR, MR, JT. Final approval of the version to be published: HW, VR, MR, JT.

\section{Compliance with ethical standards}

Conflict of interest The authors declare no competing interests.

Publisher's note Springer Nature remains neutral with regard to jurisdictional claims in published maps and institutional affiliations.

\section{References}

1. Naderi K, Maubon L, Jameel A, Patel DS, Gormley J, Shah V, et al. Attitudes to cataract surgery during the COVID-19 pandemic: a patient survey. Eye. 2020;34:2161-2.

2. Lin P-F, Naveed H, Eleftheriadou M, Purbrick R, Zarei Ghanavati M, Liu C. Cataract service redesign in the post-COVID-19 era. Br J Ophthalmol. 2020. https://doi.org/10.1136/bjophtha lmol-2020-316917.

3. Ahmed IIK, Hill WE, Arshinoff SA. Bilateral same-day cataract surgery: an idea whose time has come \#COVID-19. Ophthalmology. 2021;128:13-4.

4. Immediate Sequential Bilateral Cataract Surgery (ISBCS) during COVID recovery: RCOphth/UKISCRS rapid advice document. https://www.rcophth.ac.uk/wp-content/uploads/2020/07/Immedia te-Sequetial-Bilateral-Cataract-Surgery-Guidance-2.pdf. 